\title{
Changes in Concurrent Opioid and Benzodiazepine Use Following a Low-Touch Prescriber Fax Intervention
}

\author{
Rochelle Yang, PharmD; Sara E. Carruth, PharmD; Wenyi (Amanda) Qiu, MS;
} and R. Scott Leslie, PhD, MPH

\begin{abstract}
BACKGROUND: Concurrent use of opioids and benzodiazepines (COB) can lead to additive respiratory and central nervous system effects, putting patients at increased risk of fatal overdose. In 2016, the Centers for Disease Control and Prevention released an opioid-prescribing guideline recommending against COB, and the Pharmacy Quality Alliance (PQA) endorsed a COB measure in its core opioid set. From May 1, 2017, to December 4, 2017, a California Medicaid plan launched a COB-focused prescriber outreach intervention for members receiving recent opioid and benzodiazepine claims with the intent of decreasing concurrent use.
\end{abstract}

OBJECTIVE: To assess the effect of a prescriber fax intervention by a Medicaid plan on COB.

METHODS: Two retrospective analyses were conducted using administrative pharmacy claims data: a comparison of the PQA COB rate among selected California Medicaid plans for 2016 and 2017 and a cohort utilization analysis of members identified for the fax intervention compared with controls. Intervention and control members were matched based on 12 pre-index utilization characteristics. Outcomes assessed included proportion of members with resolution of $\mathrm{COB}$ in the post-index period, change in mean number of $\mathrm{COB}$ days before and after the index date, and proportion of members with decreased benzodiazepine daily dose after the index date. Analyses were also performed for the subgroups of members with $<30$ days of $\mathrm{COB}$ and $\geq 30$ days of $\mathrm{COB}$ in the pre-index period.

RESULTS: All California Medicaid plans in the study saw an improvement in the PQA COB rate between 2016 and 2017. In the utilization analysis, 4,182 intervention members were eligible according to study criteria and matched to similar control members. Many differences in medication use existed between the subgroups with $<30$ days and $\geq 30$ days of $\mathrm{COB}$ in the pre-index period, with the latter group consisting of much more chronic, complex users. The intervention cohort had a statistically significant higher proportion of members with complete resolution of $\mathrm{COB}$ compared with the control cohort ( $43.8 \%$ vs. $40.0 \%$; $P<0.01$ ), which was also statistically significant for the 2 subgroups. The intervention cohort had a decrease in the mean number of COB days from pre- to post-index periods, but this was only statistically significant for the subgroup with $<30$ COB days ( -2.5 vs. -1.5 ; $P=0.0217)$. No statistically significant differences were detected between cohorts in proportion of members with decreased benzodiazepine dose.

CONCLUSIONS: Our analyses demonstrated that this low-touch prescriber fax intervention produced statistically significant improvements in $\mathrm{COB}$ outcomes, despite the overall trend of declining $\mathrm{COB}$ among the other California Medicaid plans. Low-touch, targeted prescriber outreach can be an inexpensive yet effective tool to affect prescriber behavior, particularly before $\mathrm{COB}$ becomes chronic.

J Manag Care Spec Pharm. 2020;26(2):160-67

Copyright $\odot 2020$, Academy of Managed Care Pharmacy. All rights reserved.

\section{What is already known about this subject}

The Centers for Disease Control and Prevention has cautioned against the concurrent use of opioids and benzodiazepines (COB), and the Pharmacy Quality Alliance (PQA) has endorsed a COB quality measure.

Pre-post outcomes studies have found that low-touch interventions may be effective in changing prescriber behavior. Opioid prescribing has declined over the past several years, which may be attributed to shifting prescribing practices, changing regulatory requirements, and increased public awareness of opioids.

\section{What this study adds}

The PQA COB rate among 7 California managed Medicaid plans improved from 2016 to 2017, with decreases in the prevalence of COB among opioid users ranging from $0.5 \%$ to $1.9 \%$.

The California Medicaid population that received the prescriber fax intervention had a greater improvement in COB resolution compared with a matched control cohort (43.8\% vs. $40.0 \%$ ), providing evidence that a low-touch, prescriber fax notification may contribute to the resolution of this dangerous drug combination. There was a greater difference in $\mathrm{COB}$ resolution between intervention and control cohorts in members with fewer than 30 days of $\mathrm{COB}$ compared with members with 30 or more days of $\mathrm{COB}$, suggesting that the prescriber fax intervention may be less effective in members with more chronic COB.

T he use of concurrent opioids and benzodiazepines (COB) creates an additive risk of respiratory and central nervous system depression for patients, which could lead to potentially fatal overdose., ${ }^{1,2}$ Patients with COB have an estimated 5 -fold increase in overdose risk compared with patients prescribed opioids alone. ${ }^{3}$ The prevalence of this dangerous drug combination increased from the mid-1990s through 2014.4.5 One study of U.S. veterans from the Veterans Affairs Administration database found $\mathrm{COB}$ to be present in approximately $30 \%$ of opioid users. ${ }^{6}$ Another study of outpatient prescriptions in Pennsylvania found that almost half of patients taking opioids were also prescribed benzodiazepines. ${ }^{7}$ In March 2016, the Centers for Disease Control and Prevention (CDC) released a guideline on the appropriate prescribing of opioids for chronic pain that advised against COB whenever 
possible and recommended that prescribers carefully weigh the risks and benefits before prescribing this combination. ${ }^{1}$ In December 2016, the Pharmacy Quality Alliance (PQA) endorsed a COB measure in its Opioid Core Measure Set ${ }^{8}$; this measure was also adopted by the National Quality Forum (NQF) in October 2018. ${ }^{9}$

Because inappropriate opioid use has gained attention in recent years, various stakeholders have adopted strategies to combat misuse. Federal agencies, many state health departments, and public and private managed care organizations have implemented initiatives, such as limiting quantity for initial opioid fills ${ }^{10}$ conducting retrospective drug utilization reviews, ${ }^{11-13}$ and creating "lock-in" programs that limit highrisk patients to a single prescriber and pharmacy for controlled substance prescriptions. ${ }^{14}$ Interventions focused on changing behavior can be low touch, such as automated provider mailings, or high touch, such as one-on-one case management with the member. In 2017, a California Medicaid plan conducted a low-touch fax intervention, notifying opioid prescribers of members' recent benzodiazepine fills and the CDC recommendations regarding COB. The purpose of this study was to assess the effect of this fax intervention on $\mathrm{COB}$ use.

\section{Methods}

Between May 1, 2017, and December 4, 2017, an automated daily claims sweep identified members of a large California Medicaid plan who had filled an opioid prescription with at least 1 benzodiazepine claim in a 30-day lookback from the date of the opioid claim. The member's opioid prescriber was automatically faxed a letter notifying the prescriber of the recent benzodiazepine fill and providing information about the CDC opioid prescribing guideline's precautions regarding COB. The prescriber was asked to fax the form back with a response that indicated the following: "action will be taken" or "no action needed-patient will be monitored." Prescribers who did not return a response were sent a second fax 3 weeks later. No additional faxes were sent following this second fax.

Two retrospective analyses were conducted: a plan-level quality measure calculation and a member-level COB utilization analysis. The data sources were pharmacy claims and eligibility information from the MedImpact database. MedImpact is a pharmacy benefits manager (PBM) that provides pharmacy benefits for 28 million lives globally and services all plans included in this study. The opioid and benzodiazepine drug lists used for this analysis mirrored those used by PQA in the $\mathrm{COB}$ reporting measure, which included all opioids with morphine milligram equivalents. ${ }^{8}$

\section{Population Quality Measure Assessment by Plan}

The PQA COB rates for calendar years 2016 and 2017 were calculated for the plan that conducted the $\mathrm{COB}$ intervention ("intervention plan") and each of the 6 other California Medicaid plans that did not implement this intervention ("other plans"). The PQA COB rate is reported based on calendar year and defined as the number of adults from the denominator with at least 2 benzodiazepine claims on at least 2 different days with a total cumulative days supply greater than or equal to 30 (numerator), divided by number of adults with at least 2 opioid claims on at least 2 different days and a total cumulative days supply of at least 15 (denominator). ${ }^{8}$

\section{COB Utilization Cohort Study}

Members who had been identified for the prescriber fax intervention and had at least 1 day of overlap between an opioid and a benzodiazepine in a 30-day look-back were included in the intervention cohort. Members from the other California Medicaid plans who had filled an opioid between May 1, 2017, and December 4, 2017, with at least 1 day of benzodiazepine overlap in a 30-day look-back were candidates for the control cohort. The target opioid claim for both cohorts was the first opioid claim filled between May 1, 2017, and December 4, 2017, which was the claim that triggered the prescriber letter for the intervention cohort. If multiple opioid claims were filled on the same day, the claim with the longest days supply was used as the target opioid claim. The measurement period consisted of a 90-day pre-index period followed by a 90-day post-index period, with the index date falling on the last day supply of the target opioid claim. Thus, day 1 of the post-index period immediately followed the last remaining day supply of the target opioid claim. The reason for this placement of the index date and post-index period is to observe whether the fax intervention affected the occurrence of subsequent claims after the days supply of the target opioid claim had expired. All members were required to be continuously eligible during the 180-day measurement period. Members were excluded if they had claims for cancer medications or claims filled at long-term care pharmacies during the measurement period.

Intervention and control members in the cohort analysis were matched 1:1 based on 12 characteristics in the pre-index period as shown in Table 1 . The characteristics were selected based on known or potential association with opioid disease burden and likelihood of opioid tolerance and abuse. ${ }^{15-23}$ Use of long-acting opioids and use of opioids with opioid potentiators have been found to be associated with a lower likelihood of opioid discontinuation. ${ }^{18,20,21}$ Other indicators of more chronic use, such as greater days supply of opioids and benzodiazepines, were included in the propensity score. The number of pharmacies and prescribers has been used as a risk measure in identifying potential opioid misuse. ${ }^{22,23}$

The total number of prescription drugs dispensed was used as a proxy of disease burden in the absence of diagnosis data. ${ }^{24}$ Age and presence or absence of long-acting opioids were 
TABLE 1 Pre-Index Matching Characteristics for All Matched Intervention and Control Members

\begin{tabular}{|c|c|c|c|}
\hline Characteristic & Intervention $(\mathrm{n}=4,182)$ & Control $(n=4,182)$ & $P$ Value \\
\hline Average age in years $(\mathrm{n}, \mathrm{SD})$ & $47.6 \quad(11.6)$ & $47.4 \quad(11.8)$ & 0.428 \\
\hline Members who are female (n, \%) & $2,881 \quad(68.9)$ & $2,881 \quad(68.9)$ & 1 \\
\hline Days supply of target opioid claim (n, SD) & $19.9(11.3)$ & $19.9(11.5)$ & 0.924 \\
\hline Days supply of target BZD claima $(n, S D)$ & $23.3(10.0)$ & $23.4 \quad(10.3)$ & 0.658 \\
\hline Average number of COB days (n, SD) & $32.9(28.3)$ & $33.3(27.8)$ & 0.525 \\
\hline Average number of days covered by opioid (n, SD) & $47.3(33.2)$ & $47.5(32.0)$ & 0.765 \\
\hline Average number of days covered by BZD (n, SD) & $47.3(28.4)$ & $48.0(28.9)$ & 0.302 \\
\hline Average number of unique prescribers of opioid and BZD (n, SD) & $1.7 \quad(0.8)$ & $1.7 \quad(0.9)$ & 0.542 \\
\hline Average number of unique pharmacies for opioid and BZD fills (n, SD) & $1.2 \quad(0.5)$ & $(0.5)$ & 0.305 \\
\hline Average number of unique medication taken by member (n, SD) & $(5.3)$ & $(5.5)$ & 0.847 \\
\hline Members with $\geq 1$ long-acting opioid fill (n, \%) & $1,510 \quad(36.1)$ & $1,510 \quad(36.1)$ & 1 \\
\hline Members with $\geq 1$ opioid potentiatorb fill (n, \%) & $1,464 \quad(35.0)$ & $1,497 \quad(35.8)$ & 0.437 \\
\hline
\end{tabular}

aTarget BZD claim defined as the most recent approved benzodiazepine claim in the pre-index period.

${ }^{b}$ Opioid potentiators defined as muscle relaxants, nonbenzodiazepine sedatives, gabapentin, and pregabalin.

$B Z D=$ benzodiazepine; $C O B=$ concurrent use of opioids and benzodiazepines; $S D=$ standard deviation.

matched exactly. The 10 other characteristics were included in a propensity score calculated using PROC PS Match, SAS version 9.4 (SAS Institute, Cary NC) and paired using optimal propensity score matching. Members who could not be matched were removed from further analysis.

The primary outcome for this analysis was the percentage of members with complete $\mathrm{COB}$ resolution, defined as having no days of $\mathrm{COB}$ in the post-index period. Secondary outcomes included the percentage of members with decreased benzodiazepine dose and change in mean number of $\mathrm{COB}$ days from pre- to post-index. A decrease in benzodiazepine dose was defined as a decrease in average dose per day of the last benzodiazepine claim in the pre-index period. Average dose per day was calculated as the drug strength multiplied by the quantity divided by days supply. Members with no benzodiazepine use in the post-index period were not included in the dose decrease outcome.

Two subgroups of the intervention and control cohorts were also compared for each outcome: matched members with fewer than 30 days of $\mathrm{COB}(<30 \mathrm{COB})$ in the pre-index period and matched members with 30 or more days of $\mathrm{COB}$ ( $\geq 30 \mathrm{COB}$ ) in the pre-index period. Descriptive statistics were expressed as means with standard deviations for continuous variables and frequencies with percentages for binary data. Pre-post outcomes were compared with repeated measures analysis of variance using the interaction of case and time to estimate the difference-in-difference of means. The a priori alpha was set at 0.05 to determine statistical significance. Number needed to treat (NNT) was calculated by taking the inverse of the absolute risk reduction. Data management and analyses were conducted using SAS version 9.4 .

\section{Results}

The PQA COB rates were calculated for the intervention plan and 6 comparison plans as shown in Figure 1. The COB rate decreased for all plans in the study between 2016 and 2017, with decreases ranging from $0.17 \%$ to $4.96 \%$. The PQA COB rate for the intervention plan decreased by $0.83 \%$, from $18.3 \%$ to $17.5 \%$.

A total of 5,444 members were identified in the fax intervention. A prescriber response was received for 1,492 (27.4\%) of the 5,444 unique prescriber letters sent. Of the 1,492 responses returned, there were 427 (28.6\%) responses of "action will be taken" and 1,065 (71.4\%) responses of "no action is necessary -patient will be monitored."

In the cohort analysis, 4,182 intervention members were eligible according to study criteria and matched to control members. Table 1 and Table 2 summarize the demographics and clinical characteristics of the intervention and control cohorts. The pre-index characteristics between the intervention and control groups, including in the $<30 \mathrm{COB}$ and $\geq 30$ COB subgroups, were comparable with $P$ values $>0.2$. The cohorts consisting of all matched members had a mean of 33 days of $\mathrm{COB}$ in the pre-index period. The $<30$ COB subgroup had a mean of 9 days of $\mathrm{COB}$ in the pre-index period, whereas the $\geq 30$ COB subgroup had a mean of 58 days. The $\geq 30$ COB subgroup also had a much higher rate of members on long-acting opioids (45\% vs. 28\%) and opioid potentiators (40\% vs. $30 \%$ ). The number of unique prescribers and number of unique pharmacies were similar between the $<30$ COB and $\geq 30$ COB subgroups.

For the primary outcome of percentage of members with complete $\mathrm{COB}$ resolution in the post-index period, the intervention group had a statistically significant higher rate of members with no COB days in the post-index period $(43.8 \%$, 
FIGURE 1 PQA COB Rates in 2016 and 2017 for Intervention Plan and 6 Other Comparison Plans

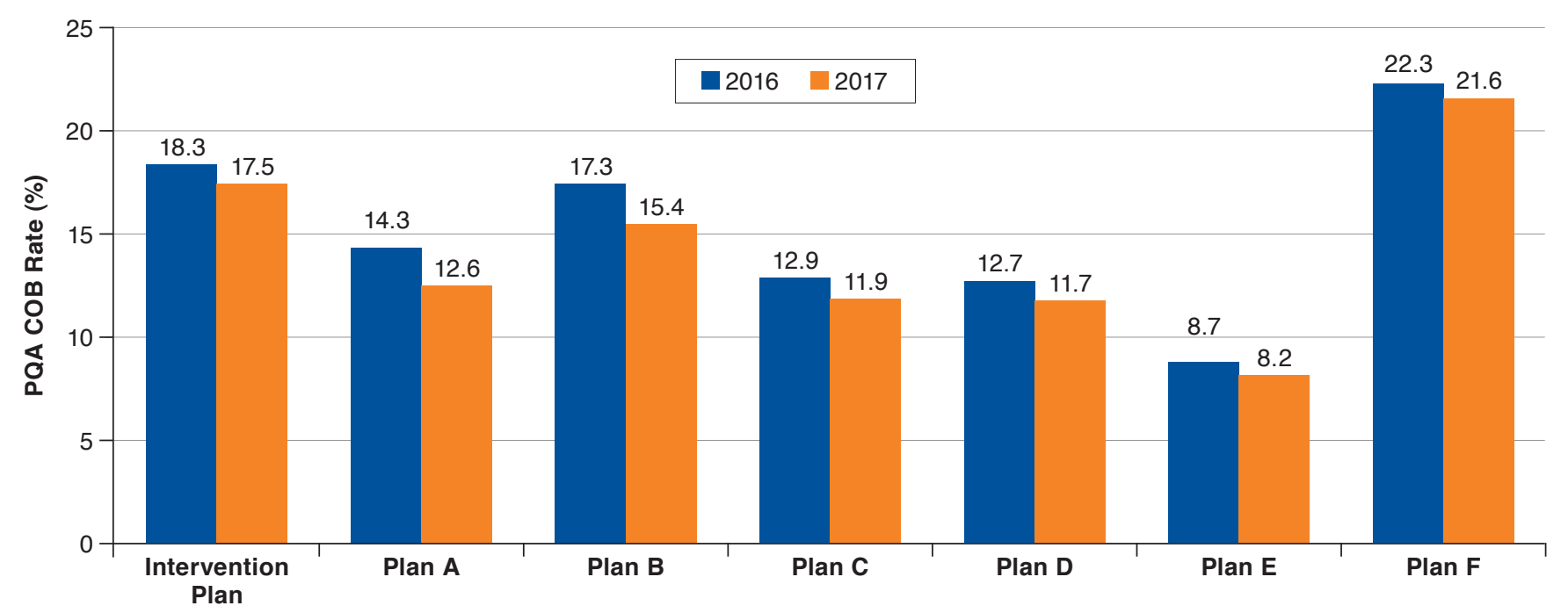

$C O B=$ concurrent use of opioids and benzodiazepines; PQA = Pharmacy Quality Alliance.

95\% confidence interval $[\mathrm{CI}]=42.3 \%-45.3 \%)$ compared with the control group (40.0\%, 95\% CI=38.5\%-41.5\%; $P=0.0004)$. The NNT for the intervention was 26.1 (95\% CI=11.7-40.6) in a 90-day follow-up period. For every 27 members with COB targeted by the fax intervention, we could achieve 1 additional member who had COB resolution compared with no fax intervention. The intervention cohort also had a higher rate of no post-index $\mathrm{COB}$ days when looking at the $<30$ and $\geq 30 \mathrm{COB}$ subgroups. In the $<30 \mathrm{COB}$ subgroup, there were $3.5 \%$ more members in the intervention cohort who discontinued COB in the post-index period compared with the matched control cohort $(P=0.0123)$, with an NNT of $28.6(95 \% \mathrm{CI}=6.2-51.0)$. In the $\geq 30 \mathrm{COB}$ subgroup, $2.5 \%$ more intervention members had discontinued COB compared with control members $(P=0.0222)$, with an NNT $=41.5(95 \% \mathrm{CI}=6.0-77.1)$.

The average number of $\mathrm{COB}$ days from the pre- to postindex periods decreased more in the intervention group $(-2.5$ days) than in the control group but was only statistically significant for the $<30$ COB subgroup, with a change of -2.5 $(95 \% \mathrm{CI}=-3.0,-1.9)$ days for the intervention and $-1.5(95 \%$ $\mathrm{CI}=-2.12,-0.97)$ days for the control group $(P=0.0217)$. The percentage of members with decreased benzodiazepine dose in the post-index period was greater in the intervention cohort compared with the control group but did not meet statistical significance $(9.5 \%, 95 \% \mathrm{CI}=8.6 \%-10.4 \%$ intervention vs. $8.4 \%$, $95 \% \mathrm{CI}=7.5 \%-9.2 \%$ control; $P=0.0603$ ).

\section{Discussion}

The PQA COB rates for all California Medicaid plans in the study decreased between 2016 and 2017, indicating that prescribing and utilization patterns were shifting towards decreased $\mathrm{COB}$ during this time period. Changing prescribing patterns may have been influenced by other programs or initiatives around COB that were being implemented by the Medicaid health plan or the spillover effect from other payer initiatives that targeted the same prescribers. ${ }^{25}$

Our cohort analysis showed that the cohort that received the low-touch prescriber fax intervention was associated with a greater proportion of members having complete COB resolution compared with the matched control cohort, while the NNT to achieve this outcome was relatively low. Differences in $\mathrm{COB}$ resolution were statistically significant among all matched cohorts, including the $<30$ pre-index $\mathrm{COB}$ and $\geq 30$ pre-index COB days subgroups (Table 3). In addition, we saw positive outcomes of the intervention despite only receiving a response back from one quarter of the prescriber letters, many of which were marked "no action needed-patient will be monitored." Not responding to the letter from the PBM did not preclude prescribers attempting to resolve $\mathrm{COB}$ in their patients.

The decrease in the average number of $\mathrm{COB}$ days in the post-index period was only statistically significant for the $<30$ $\mathrm{COB}$ subgroup compared with the matched control cohort. Although none of the 3 cohorts compared showed statistically significant differences compared with the control group for the outcome of decreasing the benzodiazepine dose, the $<30$ $\mathrm{COB}$ subgroup had a greater difference in the proportion of 


\begin{tabular}{|c|c|c|c|c|c|c|}
\hline \multirow{3}{*}{$\begin{array}{l}\text { Characteristic } \\
\text { Average age in years }(n, S D)\end{array}$} & \multicolumn{3}{|c|}{$<30$ COB Days in Pre-Index Period } & \multicolumn{3}{|c|}{$\geq 30$ COB Days in Pre-Index Period } \\
\hline & $\begin{array}{c}\text { Intervention } \\
(\mathbf{n}=2,147)\end{array}$ & $\begin{array}{c}\text { Control } \\
(\mathrm{n}=2,147)\end{array}$ & \multirow{2}{*}{$\begin{array}{c}P \\
\text { Value }\end{array}$} & $\begin{array}{c}\text { Intervention } \\
(\mathbf{n}=2,035)\end{array}$ & $\begin{array}{l}\text { Control } \\
(\mathrm{n}=2,035)\end{array}$ & \multirow{2}{*}{$\begin{array}{c}P \\
\text { Value }\end{array}$} \\
\hline & $44.9(12.2)$ & $45.0 \quad(13.0)$ & & $50.40 \quad(10.2)$ & $50.4 \quad(10.0)$ & \\
\hline Members who are female (n, \%) & $1,483 \quad(69.1)$ & $1,483 \quad(69.1)$ & 1 & $1,398 \quad(68.7)$ & $1,398 \quad(68.7)$ & 1 \\
\hline Days supply of target opioid claim $(n, S D)$ & $12.4 \quad(10.7)$ & $12.4(10.5)$ & 0.980 & $27.8 \quad(5.5)$ & $27.8 \quad(5.2)$ & 0.745 \\
\hline Days supply of target BZD claima $(n, S D)$ & $18.7(11.3)$ & $18.7(11.8)$ & 0.873 & $(5.1)$ & $(5.5)$ & 0.776 \\
\hline Average number of COB days (n, SD) & $8.9 \quad(7.9)$ & $9.0 \quad(7.8)$ & 0.602 & $58.2(18.2)$ & $58.1 \quad(18.4)$ & 0.861 \\
\hline Average number of days covered by opioid (n, SD) & $23.7 \quad(27.0)$ & $23.7(25.5)$ & 0.991 & $72.2 \quad(17.0)$ & $72.5 \quad(16.9)$ & 0.515 \\
\hline Average number of days covered by BZD (n, SD) & $31.0 \quad(27.0)$ & $32.2(28.6)$ & 0.184 & $64.5 \quad(17.8)$ & $63.9 \quad(18.1)$ & 0.307 \\
\hline Average number of unique prescribers of opioid and BZD (n, SD) & $1.8 \quad(0.8)$ & $1.8 \quad(0.9)$ & 0.368 & $1.6 \quad(0.8)$ & $1.6 \quad(0.8)$ & 0.244 \\
\hline Average number of unique pharmacies for opioid and BZD fills (n, SD) & $(0.6)$ & $(0.6)$ & 0.678 & $(0.5)$ & $(0.5)$ & 0.323 \\
\hline Average number of unique medication taken by member (n, SD) & $8.8 \quad(5.1)$ & $8.9 \quad(5.3)$ & 0.511 & $10.2 \quad(5.5)$ & $(5.7)$ & 0.502 \\
\hline Members with $\geq 1$ long-acting opioid fill (n, \%) & $591 \quad(27.5)$ & $591 \quad(27.5)$ & 1 & $917 \quad(45.1)$ & $917 \quad(45.1)$ & 1 \\
\hline Members with $\geq 1$ opioid potentiatorb fill (n, \%) & $652(30.3)$ & $640 \quad(29.8)$ & 0.690 & $813 \quad(40.0)$ & $836 \quad(41.1)$ & 0.463 \\
\hline
\end{tabular}

members with decreased benzodiazepine dose than the group with the $\geq 30 \mathrm{COB}$ subgroup when compared with controls. Based on the pre-index characteristics in Table 2, it is apparent that the members in the $<30 \mathrm{COB}$ subgroup were much different than the members in the $\geq 30 \mathrm{COB}$ subgroup. The $\geq 30$ COB subgroup consisted of members with more chronic, complex opioid and benzodiazepine use who showed a smaller improvement in the outcomes of reduction in COB days from the pre- to post-index periods and decrease in benzodiazepine dose. Members with more chronic COB may require a higher touch intervention to affect $\mathrm{COB}$ outcomes.

Current literature shows mixed results from low-touch prescriber letter interventions. ${ }^{26-30}$ Our results suggest that low-touch fax interventions may be a useful tool in shifting prescriber behavior in cases of COB. Studies on various types of opioid-related interventions in the past several years have demonstrated generally positive results ${ }^{11-13,26}$; however, it is important to note that, in many of these studies, the outcomes that were evaluated used a pre-post study design. It is important to consider that many external factors that could affect use were also occurring, such as legislative rulings around opioid control, ${ }^{31-33}$ increased media coverage of the opioid epidemic, ${ }^{34,35}$ and increased public awareness. ${ }^{36,37}$ Indeed, 1 study found a $22 \%$ decrease in overall opioid prescriptions between 2013 and 2017.38

In order to discern the true effect of 1 particular opioidrelated intervention, it is important to use a carefully selected control group rather than historical pre-intervention utilization measures as a control. In our analysis, we attempted to control for such external factors by matching to members with similar opioid and opioid-potentiator use from program-naive
California Medicaid plans. The effect of this COB intervention was found to be statistically significant for the primary outcome compared with matched cohorts from other California Medicaid plans with decreasing PQA COB rates.

\section{Limitations}

There are some limitations of this study that should be considered. First, although we made our best attempt at gathering information regarding possible opioid clinical programs at the selected comparison plans, as a PBM we did not have full insight into initiatives occurring at the plan or institution level. The ideal control plan would not have any opioid or COB programs in place during our measurement period. However, it is likely that the other California managed Medicaid plans were implementing initiatives that may have lessened our ability to detect the effect of this particular COB intervention.

Second, prescribers are able to issue multiple prescriptions for up to a 90-day supply of opioids (1 present-day 30-day prescription with 2 future dated 30-day prescriptions) and up to 5 refills on benzodiazepine prescriptions. ${ }^{39}$ The effect of the intervention may not have been detected for members refilling prescriptions already in their possession and not returning for a follow-up until after their refills had been exhausted. Many members may not have seen their prescribers for a follow-up visit where discontinuation of COB can be discussed until after the measurement period for this study. Thus, the full effect of the intervention may not have been realized until after the post-index period.

Third, members were identified for the intervention regardless of days supply of the claims or type of prescriber. For instance, a member filling a benzodiazepine for pre-procedure 
TABLE 3 Outcomes of COB Utilization Cohort Study

\begin{tabular}{|c|c|c|c|c|c|}
\hline \multicolumn{6}{|c|}{ Percentage of members with resolution of $\mathrm{COB}$ (no COB in the post-index period) } \\
\hline Subgroup & Intervention or Control & Members with Res & lution of $\mathrm{COB}(\mathrm{n}, \%)$ & \multicolumn{2}{|c|}{$P$ Value ${ }^{a}$} \\
\hline \multirow{2}{*}{ All matched members } & Intervention $(n=4,182)$ & 1,833 & $(43.8)$ & \multirow{2}{*}{\multicolumn{2}{|c|}{$<0.001$}} \\
\hline & Control $(n=4,182)$ & 1,673 & $(40.0)$ & & \\
\hline \multirow{2}{*}{$<30$ pre-index COB days } & Intervention $(\mathrm{n}=2,147)$ & 1,545 & (72.0) & \multirow{2}{*}{\multicolumn{2}{|c|}{0.012}} \\
\hline & Control $(n=2,147)$ & 1,470 & $68.5)$ & & \\
\hline \multirow{2}{*}{$\geq 30$ pre-index COB days } & Intervention $(\mathrm{n}=2,035)$ & 288 & $(14.2)$ & \multirow{2}{*}{\multicolumn{2}{|c|}{0.022}} \\
\hline & Control $(n=2,035)$ & 238 & $(11.7)$ & & \\
\hline \multicolumn{6}{|c|}{ Mean number of $\mathrm{COB}$ days from pre-index period to post-index period } \\
\hline Subgroup & Intervention or Control & $\begin{array}{l}\text { Pre-Index COB } \\
\text { Days (Mean, SD) }\end{array}$ & $\begin{array}{l}\text { Post-Index COB } \\
\text { Days (Mean, SD) }\end{array}$ & $\begin{array}{l}\text { Difference } \\
\text { (Days) }\end{array}$ & $P$ Value ${ }^{a}$ \\
\hline \multirow{2}{*}{ All matched members } & Intervention $(n=4,182)$ & $32.9(28.3)$ & $26.0(29.6)$ & -6.9 & \multirow{2}{*}{0.153} \\
\hline & Control $(n=4,182)$ & $33.3(27.8)$ & $27.0(28.9)$ & -6.3 & \\
\hline \multirow{2}{*}{$<30$ pre-index COB days } & Intervention $(\mathrm{n}=2,147)$ & $8.9 \quad(7.9)$ & $6.4(14.4)$ & -2.5 & \multirow{2}{*}{0.022} \\
\hline & Control $(n=2,147)$ & $9.0 \quad(7.8)$ & $7.4(15.4)$ & -1.5 & \\
\hline \multirow{2}{*}{$\geq 30$ pre-index COB days } & Intervention $(\mathrm{n}=2,035)$ & $58.2(18.2)$ & $46.6(27.3)$ & -11.6 & \multirow{2}{*}{0.828} \\
\hline & Control $(n=2,035)$ & $58.1(18.4)$ & $46.7(26.1)$ & -11.4 & \\
\hline \multicolumn{6}{|c|}{ Percentage of members with a decrease in BZD dose from pre-index period to post-index period } \\
\hline Subgroup & Intervention or Control & \multicolumn{2}{|c|}{$\begin{array}{l}\text { Members with decreased } \\
\text { BZD dose }(n, \%)\end{array}$} & \multicolumn{2}{|c|}{$P$ Value } \\
\hline \multirow{2}{*}{ All matched members } & Intervention $(n=4,182)$ & 398 & $(9.5)$ & \multirow{2}{*}{\multicolumn{2}{|c|}{0.060}} \\
\hline & Control $(n=4,182)$ & 349 & $(8.4)$ & & \\
\hline \multirow{2}{*}{$<30$ pre-index COB days } & Intervention $(\mathrm{n}=2,147)$ & 183 & $(8.5)$ & \multirow{2}{*}{\multicolumn{2}{|c|}{0.196}} \\
\hline & Control $(n=2,147)$ & 160 & $(7.5)$ & & \\
\hline \multirow{2}{*}{$\geq 30$ pre-index COB days } & Intervention $(\mathrm{n}=2,035)$ & 215 & $(10.6)$ & \multirow{2}{*}{\multicolumn{2}{|c|}{0.681}} \\
\hline & Control $(\mathrm{n}=2,035)$ & 207 & $(10.2)$ & & \\
\hline
\end{tabular}

aBold $P$ values indicate statistical significance.

$B Z D=$ benzodiazepine; $C O B=$ concurrent use of opioids and benzodiazepines; $S D=$ standard deviation.

anxiety and a short course of opioids intended for after the procedure may not have true concomitant use. The percentage of members with resolution of $\mathrm{COB}$ must be interpreted with caution, as it may have included members who would not have used $\mathrm{COB}$ chronically. In addition, we did not have diagnosis data for which to evaluate the clinical indication for opioid and benzodiazepine use. We also did not assess for prescriber specialty or type of practice.

Finally, we performed our analysis based on the days supply information submitted in the opioid and benzodiazepine claims; however, we could not account for members taking the medication differently than prescribed, which could have changed the true days supply for the claim.

\section{Conclusions}

The prescriber fax intervention was associated with a decrease in $\mathrm{COB}$ in a California Medicaid population compared with a similar control cohort. Our retrospective matched cohort analysis demonstrated that the intervention was able to increase the proportion of members who discontinued any COB by $3.8 \%$ over the control group, despite the fact that the plans to which these control group members belonged also had decreasing COB rates.
Discontinuation of COB can help patients reduce their risk of profound sedation, respiratory depression, and/or death from the additive effects of opioids and benzodiazepines. ${ }^{1,2}$ Such low-touch prescriber fax interventions are relatively inexpensive and easy to implement in a managed care setting.

Our analysis reinforces the idea that low-touch interventions are able to affect prescribing practices and use, particularly before COB becomes chronic. Future research in this area should focus on characteristics of members, prescribers, and claims that are most predictive of positive response and improved outcomes to further increase the effectiveness of the intervention.

\section{Authors}

ROCHELLE YANG, PharmD; SARA E. CARRUTH, PharmD; WENYI (AMANDA) QIU, MS; and R. SCOTT LESLIE, PhD, MPH, MedImpact Healthcare Systems, San Diego, California.

AUTHOR CORRESPONDENCE: Sara E. Carruth, PharmD, MedImpact Healthcare Systems, 10181 Scripps Gateway Ct., San Diego, CA 92131. Tel.: 858.790.7494; E-mail: sara.carruth@medimpact.com. 


\section{DISCLOSURES}

No outside funding was used to support this study. The authors do not have any financial relationships or potential conflicts of interest relevant to this article to disclose. At the time of conducting this research, all authors were employees of MedImpact Healthcare Systems.

The results of this study were presented at the AMCP Managed Care \& Specialty Pharmacy Annual Meeting 2019; March 25-28, 2019; San Diego, CA.

\section{ACKNOWLEDGMENTS}

The authors thank the following individuals for their assistance throughout all aspects of the study and their help in reviewing the manuscript: Bimal Patel, PharmD, MS, and Lucille Sun, PharmD, MS.

\section{REFERENCES}

1. Dowell D, Haegerich TM, Chou R. CDC Guideline for prescribing opioids for chronic pain-United States, 2016. MMWR Recomm Rep. 2016;65(1):1-49.

2. U.S. Food and Drug Administration. FDA warns about serious risks and death when combining opioid pain or cough medicines with benzodiazepines; requires its strongest warning. Drug safety communications. Updated September 20, 2017. Available at: https://www.fda.gov/drugs/drug-safety-andavailability/fda-drug-safety-communication-fda-warns-about-serious-risksand-death-when-combining-opioid-pain-or. Accessed December 31, 2019.

3. Hernandez I, He M, Brooks MM, Zhang Y. Exposure-response association between concurrent opioid and benzodiazepine use and risk of opioid-related overdose in Medicare Part D beneficiaries. JAMA Netw Open. 2018;1(2):e180918

4. Hirschtritt ME, Delucchi KL, Olfson M. Outpatient, combined use of opioid and benzodiazepine medications in the United States, 1993-2014. Prev Med Rep. 2017;9:49-54.

5. Vozoris NT. Benzodiazepine and opioid co-usage in the U.S. population, 1999-2014: an exploratory analysis. Sleep. 2019;42(4):zsy264.

6. Park TW, Saitz R, Canoczy D, et al. Benzodiazepine prescribing patterns and deaths from drug overdose among US veterans receiving opioid analgesics: case-cohort study. BMJ. 2015;350:h2698.

7. Simon J, Gehret J, Stolzenberg D, et al. Concomitant use of opioids and benzodiazepines in the outpatient setting: a retrospective study. PM R. 2019;11(4):331-456, el-e5.

8. Pharmacy Quality Alliance. PQA opioid core measure set-2019. August 2018. Available at: https://www.pqaalliance.org/assets/Measures/PQA Opioid_Core_Measure_Set_Description.pdf. Accessed December 31, 2019

9. National Quality Forum. Behavioral health and substance use, Spring 2018 cycle: CDP report. January 11, 2019. Available at: http://www.qualityforum.org/Projects/a-b/Behavioral_Health_and_Substance_Use/Final_ Report_-_Spring_2018_Cycle.aspx. Accessed December 31, 2019.

10. Riggs CS, Billups SJ, Flores S, et al. Opioid use for pain management after implementation of a medicaid short-acting opioid quantity limit. J Manag Care Spec Pharm. 2017;23(3):346-54. Available at: https://www.jmcp. org/doi/10.18553/jmcp.2017.23.3.346.

11. Daubresse M, Gleason PP, Peng Y, et al. Impact of a drug utilization review program on high-risk use of prescription controlled substances. Pharmacoepidemiol Drug Saf. 2014;23(4):419-27.

12. Qureshi N, Wesolowicz LA, Liu CM, et al. Effectiveness of a retrospective drug utilization review on potentially unsafe opioid and central nervous system combination therapy. J Manag Care Spec Pharm. 2015;21(10):938-44. Available at: https://www.jmcp.org/doi/full/10.18553/jmcp.2015.21.10.938.

13. Garcia MM, Angelini MC, Thomas T, et al. Implementation of an opioid management initiative by a state Medicaid program. J Manag Care Spec Pharm. 2014;20(5):447-54. Available at: https://www.jmcp.org/doi/10.18553/ jmcp.2014.20.5.447,
14. Roberts AW, Skinner AC. Assessing the present state and potential of Medicaid controlled substances lock-in programs. J Manage Care Spec Pharm. 2014;20(5):439-46. Available at: https://www.jmcp.org/doi/10.18553/ jmcp.2014.20.5.439.

15. Shah A, Hayes CJ, Martin BC. Factors influencing long-term opioid use among opioid naive patients: an examination of initial prescription characteristics and pain etiologies. J Pain. 2017;18(11):1374-83.

16. Sun EC, Darnall BD, Baker LC, Mackey S. Incidence of and risk factors for chronic opioid use among opioid-naive patients in the postoperative period. JAMA Intern Med. 2016;167(9):1286-93.

17. Maree RD, Marcum ZA, Saghafi E, et al. A systematic review of opioid and benzodiazepine misuse in older adults. Am J Geriatr Psychiatry. 2016;24(11):949-63.

18. Yarborough BJH, Stumbo SP, Stoneburner A, et al. Correlates of benzodiazepine use and adverse outcomes among patients with chronic pain prescribed long-term opioid therapy. Pain Med. 2019;20(6):1148-55.

19. Jamison RN, Butler SF, Budman SH, et al. Gender differences in risk factors for aberrant prescription opioid use. J Pain. 2010;11(4):312-20.

20. Ives TJ, Chelminski PR, Hammet-Stabler CA, et al. Predictors of opioid misuse in patients with chronic pain: a prospective cohort study. BMC Health Serv Res. 2006;6:46.

21. Cochran BN, Flentje A, Heck NC, et al. Factors predicting development of opioid use disorders among individuals who receive an initial opioid prescription: mathematical modeling using a database of commercially-insured individuals. Drug Alchol Depend. 2014;138:202-08.

22. Walker AM, Weatherby LB, Cepeda MS, et al. Possible opioid shopping and its correlates. Clin J Pain. 2017;33(11):976-82.

23. Centers for Medicare \& Medicaid Services. Analysis of proposed opioid overutilization criteria modifications in Medicare Part D. February 1, 2017. Available at: https://www.cms.gov/Medicare/Prescription-Drug-Coverage/ PrescriptionDrugCovContra/Downloads/Proposed-Opioid-OverutilizationCriteria-Modifications-v-02012017.pdf. Accessed December 31, 2019.

24. Huntley AL, Johnson R, Purdy S, et al. Measures of multi-morbidity and morbidity burden for use in primary care and community settings: a systematic review and guide. Ann Fam Med. 2012;10(2):134-41.

25. Angalakuditi M, Gomes J. Retrospective drug utilization review: impact of pharmacist interventions on physician prescribing. Clinicoecon Outcomes Res. 2011:3:105-08

26. Luchen GG, Prohaska ES, Ruisinger JF, Melton BL. Impact of community pharmacist intervention on concurrent benzodiazepine and opioid prescribing patterns. J Am Pharm Assoc. 2019;59(2):238-42

27. Kaufman MB, Brodin KA, Sarafian A. Effect of prescriber education on the use of medications contraindicated in older adults in a managed Medicare population. J Manag Care Pharm. 2005;11(3):211-19. Available at: https://www.jmcp.org/doi/10.18553/jmcp.2005.11.3.211.

28. Okano GJ, Raskati KL. Effects of Medicaid drug utilization review intervention letters. Clin Ther. 1995;17(3):525-33.

29. Ho MJ, Venci J. Improving the success of mailed letter intervention programs to influence prescribing behaviors: a review. J Manag Care Pharm. 2012;18(8):627-49. Available at: https://www.jmcp.org/doi/10.18553/ jmcp.2005.11.3.211

30. Armstrong EP, Wang SM, Hines LE, et al. Evaluation of a drug-drug interaction: fax alert intervention program. BMC Med Inform Decis Mak. 2013;13:32.

31. Congress passes landmark opioid bill - the Comprehensive Addiction and Recovery Act (CARA). Drug Policy Alliance. July 13, 2016. Available at: http:// www.drugpolicy.org/press-release/2016/07/congress-passes-landmark-opioidbill-comprehensive-addiction-and-recovery-act. Accessed December 31, 2019.

32. National Council of State Boards of Nursing. Legislation addressing opioid epidemic becomes law. Policy briefing. October 8, 2019. Available at: https://www.ncsbn.org/13104.htm. Accessed December 31, 2019. 
33. Baker-White A. A look at state legislation limiting opioid prescriptions Association of State and Territorial Health Officials. February 23, 2017. Available at: http://www.astho.org/StatePublicHealth/A-Look-at-StateLegislation-Limiting-Opioid-Prescriptions/2-23-17. Accessed December 31, 2019.

34. Wen LS. The accidental deadly drug prescription. Wall Street Journal. March 30, 2016. Available at: https://www.wsj.com/articles/the-accidentaldeadly-drug-prescription-1459379297. Accessed December 31, 2019.

35. Salam M. The opioid epidemic: a crisis years in the making. The New York Times. October 26, 2017. Available at: https://www.nytimes. com/2017/10/26/us/opioid-crisis-public-health-emergency.html. Accessed December 31, 2019.

36. U.S. White House. Ending America's opioid crisis. Available at: https:// www.whitehouse.gov/opioids/. Accessed December 31, 2019.
37. U.S. Health and Human Services. HHS Acting Secretary declares public health emergency to address national opioid crisis. October 26, 2017. Available at: https://www.hhs.gov/about/news/2017/10/26/hhs-acting-secretary-declares-public-health-emergency-address-national-opioid-crisis.html. Accessed December 31, 2019.

38. The IQVIA Institute. Medicine use and spending in the U.S. April 19, 2018. Available at: https://www.iqvia.com/institute/reports/medicineuse-and-spending-in-the-us-review-of-2017-outlook-to-2022. Accessed December 31, 2019.

39. Drug Enforcement Administration. Pharmacists manual. Section IXvalid prescription requirements. Available at: https://www.deadiversion. usdoj.gov/pubs/manuals/pharm2/pharm_content.htm. Accessed December 31, 2019. 